\title{
Solid-Supported Robinson Annulation under Microwave Irradiation
}

\author{
Kazuhiko Takatori, Masayasu Nakayama, Naoko Futaishi, Saori Yamada, Shinobu HiRayama, and \\ Masahiro KAJIWARA* \\ Department of Medicinal Chemistry, Meiji Pharmaceutical University; 2-522-1 Noshio, Kiyose, Tokyo 204-8588, Japan \\ Received November 29, 2002; accepted January 6, 2003
}

\section{Robinson annulation on alumina occurred efficiently on heating with microwave irradiation.}

Key words Robinson annulation; microwave; alumina; solid-support; dry media

Heating of organic reaction mixtures with microwave irradiation is an easy and rapid procedure that can be used in place of conventional heating with an oil bath, water bath, or sand bath. It has been applied in the solution phase or with solid-supported dry media. ${ }^{1,2}$ We have employed the microwave-accelerated Diels-Alder reaction for the synthesis of a compactin intermediate. ${ }^{3)}$ The Diels-Alder reaction ${ }^{4)}$ and Robinson annulation ${ }^{4-7)}$ are useful methods for the synthesis of natural products consisting of fused-ring systems, such as terpenes and alkaloids. ${ }^{8)}$ In this paper, we report on solidsupported Robinson annulation under microwave irradiation. ${ }^{9)}$ The usual conditions of Robinson annulation are as follows. Michael addition of 2-methyl-1,3-cyclohexanedione (1) to methyl vinyl ketone (2) with $\mathrm{KOH}$ in refluxed methanol for $1-3 \mathrm{~h}$, and after evaporation, aldol condensation and dehydration with pyrrolidine under reflux with azeotropic distillation in benzene for $1 \mathrm{~h}$ give Wieland-Miescher ketone (3) in $63-65 \%$ yield. $^{6}$ )

In the initial investigation of Robinson annulation, 2methyl-1,3-cyclohexanedione (1) and methyl vinyl ketone (2) were absorbed on activated acidic, neutral, or basic alumina, silica gel, Florisil ${ }^{\circledR}$, or Montmorillonite K10. When alumina was used, the Michael addition proceeded at ambient temperature without microwave irradiation to afford the corresponding Michael adduct. ${ }^{10,11)}$ Activated basic alumina was the most effective. ${ }^{12,13)}$ Other supports did not promote the Michael addition even under microwave irradiation. Microwave irradiation of the mixture of the Michael adduct and basic alumina for $3 \mathrm{~min}$ in a domestic microwave oven resulted in intramolecular aldol condensation and subsequent partial dehydration to give a mixture of the Wieland-Miescher ketone (3) and alcohol 4. In the presence of a catalytic amount of pyrrolidine, the dehydration completed under microwave irradiation for $3 \mathrm{~min}$ and the reaction afforded only the Wieland-Miescher ketone (3) in 52\% yield (Fig. 1).

Microwave irradiation sufficed for the complete reaction only after addition of pyrrolidine (Table 1 entry 1 ), and the temperature immediately after microwave irradiation was $c a$. $155^{\circ} \mathrm{C}$. When this reaction was performed by heating in an oil bath at $155^{\circ} \mathrm{C}$ for $3 \mathrm{~min}$ after the addition of pyrrolidine, the annulation was not completed and afforded the Michael adduct and the ketone 3 in 33\% and 19\% yield, respectively. Microwave heating was effective for the dry media reaction.

The reaction of several structurally diverse 1,3-dicarbonyl compounds and $\alpha, \beta$-unsaturated ketones was also performed in this condition (Table 1). All the reactions proceeded rapidly. The usable 1,3-dicarbonyl compounds included 1,3diketone, $\beta$-ketoester, and $\beta$-ketoamide. The formation of
Hajos-Parrish ketone (8) and the indan derivative 10 occurred in low yield, since the reverse reaction, hydration of the double bond in the ketone $(\mathbf{8})$ followed by retro-aldol reaction, tended to occur in this condition (entries 3,4$)$. The reaction of 6-membered ring $\beta$-ketoester 11 and $\beta$-ketoamide $\mathbf{1 8}^{14)}$ with methyl vinyl ketone (2) or ethyl vinyl ketone (5) yielded good results (entries 5, 6, 9). The required microwave irradiation time and the yield were markedly dependent on the structure in the case of $\alpha, \beta$-unsaturated ketones. The simple $\alpha, \beta$-unsaturated ketone 2 reacted smoothly and the yield was good. The bulkier $\alpha$ - or $\beta$-substituted $\alpha, \beta$-unsaturated ketones 14 and 16 gave poor results (entries 7,8). This reason for this is presumably the ease of occurrence of the Michael addition. The Michael addition of the $\beta$-ketoester 11 to $\mathbf{2}$ and $\mathbf{5}$ on alumina at ambient temperature gave the adduct in $94 \%$ and $96 \%$ yield, respectively, after elution with AcOEt. On the other hand, the Michael addition of $\mathbf{1 1}$ to the bulkier $\alpha, \beta$-unsaturated ketones 14 and 16 scarcely proceeded under this condition. The reaction of $\mathbf{1 1}$ and $\mathbf{1 4}$ gave a trace amount of the adduct, and adduct formation between 11 and 16 was not detected. These reactions did not proceed easily even under microwave irradiation. ${ }^{15)}$ Therefore, simple alkyl vinyl ketones are the best choice for the $\alpha, \beta$-unsaturated ketone.

Pyrrolidine as the catalyst was required for most, but not all, of the reactions. Other secondary amines were also effective as the catalyst for the complete reaction (Table 2).

In summary, the methodology presented provides an operationally very simple and rapid Robinson annulation on activated basic alumina under microwave.

\section{Experimental}

Instruments Unless otherwise noted, all materials were obtained from commercial suppliers and used without purification. Microwave irradiation was carried out in a Mitsubishi RO-F6 domestic microwave oven $(500 \mathrm{~W}$, $2450 \mathrm{~Hz}$ ). Column chromatography and TLC were performed on silica gel

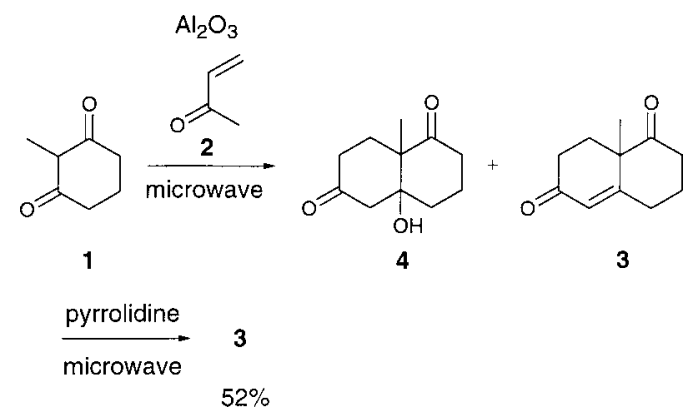

Fig. 1 
Table 1. Robinson Annulation under Microwave Irradiation

\begin{tabular}{|c|c|c|c|c|c|c|}
\hline Entry & 1,3-Dicarbonyl compound & $\alpha, \beta$-Unsaturated ketone & Pyrrolidine (eq.) & Time (min) & Product & Yield $(\%)^{a)}$ \\
\hline 1 & & 2 & 0.05 & 3 & 3 & 54 \\
\hline 2 & 1 & 5 & 0.40 & $5+2$ & 6 & 51 \\
\hline 3 & 7 & 2 & 0.07 & 3 & 8 & 45 \\
\hline 4 & 9 & 2 & 0.09 & 3 & 10 & 32 \\
\hline 5 & $\begin{array}{l}0 \\
11\end{array}$ & 2 & 0.05 & 3 & 12 & 86 \\
\hline 6 & 11 & 5 & 0.05 & 3 & 13 & 87 \\
\hline 7 & 11 & 14 & none & $3+3$ & 15 & $28^{b)}$ \\
\hline 8 & 11 & 16 & 0.05 & $3+5+7$ & 17 & $11^{c)}$ \\
\hline 9 & $\mathrm{R}=2,6$-dimethylphenyl & 2 & none & 3 & 19 & 73 \\
\hline
\end{tabular}

a) Isolated yield. b) Single isomer. The stereochemistry was not determined. c) A $1: 1$ diastereomer mixture. The ratio was estimated by ${ }^{1} \mathrm{H}-\mathrm{NMR}$ spectrum.

Table 2. Effect of Various Amines in Robinson Annulation of $\mathbf{1 1}$ and $\mathbf{2}$

\begin{tabular}{lcc}
\hline \hline Amine $(0.05$ eq) & Time $(\min )$ & Yield $(\%)$ \\
\hline Piperidine & 3 & 66 \\
Morpholine & 3 & 66 \\
Diisopropylamine & 3 & 72 \\
Diethylamine & 3 & 69 \\
\hline
\end{tabular}

$60 \mathrm{~N}$ (spherical, neutral, $40-50 \mu \mathrm{m}$, Kanto Chemical) and on percolated silica gel $60 \mathrm{~F}_{254}$ plates (Merck), respectively. Melting points ( $\mathrm{mp}$ ) were measured on a Yanaco micro melting point apparatus and are uncorrected. IR spectra were recorded on a JASCO VALOR-III Fourier-transform spectrometer. ${ }^{1} \mathrm{H}-\mathrm{NMR}$ spectra were recorded on a Varian Gemini $2000(300 \mathrm{MHz})$ Fourier-transform spectrometer. The chemical shifts are reported in $\delta$ values relative to tetramethylsilane (TMS) at $0 \mathrm{ppm}$. Electron-impact MS (EI-MS) and high resolution MS (HR-MS) were obtained with a JEOL JMS-DX-302 double-focusing spectrometer. Elemental analysis was performed with a Perkin-Elmer Model 240B elemental analyzer.

A Typical Procedure. Wieland-Miescher Ketone (3) A mixture of activated basic alumina $(4.0 \mathrm{~g}, 70-230$ mesh, Aluminum oxide 90 active, basic, Blockmann type I activity) and 2-methyl-1,3-cyclohexanedione (1, $1.00 \mathrm{~g}, 8.0 \mathrm{mmol})$ was placed in a glass or Teflon ${ }^{\mathbb{B}}$ vessel. Methyl vinyl ketone $(2,0.91 \mathrm{ml}, 11.2 \mathrm{mmol})$ was added. The mixture was shaken for $10 \mathrm{~min}$ to allow the Michael addition to proceed. Pyrrolidine $(0.03 \mathrm{ml}, 0.36 \mathrm{mmol})$ was added. The mixture was shaken for $10 \mathrm{~min}$ and irradiated with microwaves for $3 \mathrm{~min}$. The product was eluted with ethyl acetate and the eluate was evaporated. The residue was purified by column chromatography on silica gel (hexane : ethyl acetate $=2: 1$ ) to give $3(0.75 \mathrm{~g}, 54 \%)$. Activated alu- mina from Wako Pure Chemical Industries, Ltd. (200 mesh for column chromatography) could be used instead of Merck alumina.

Ethyl 6-Methyl-7-oxo-1,3,4,5,6,7-hexahydro-2 $H$-naphthalene-4a-carboxylate (15): Slightly yellow oil. IR (neat) $\mathrm{cm}^{-1}: 2936,2862,1725,1677,1631$, $1452,1368,1292,1258,1232,1203,1188,1154,1134,1087,1021,865$. ${ }^{1} \mathrm{H}-\mathrm{NMR}\left(\mathrm{CDCl}_{3}\right) \delta: 1.08(3 \mathrm{H}, \mathrm{d}, J=6.6 \mathrm{~Hz}), 1.28(3 \mathrm{H}, \mathrm{t}, J=7.1 \mathrm{~Hz}), 1.23-$ $1.48(4 \mathrm{H}, \mathrm{m}), 1.74(1 \mathrm{H}, \mathrm{m}), 1.89(1 \mathrm{H}, \mathrm{m}), 2.24-2.50(5 \mathrm{H}, \mathrm{m}), 4.17-4.29$ $(2 \mathrm{H}, \mathrm{m}), 5.91(1 \mathrm{H}, \mathrm{s})$. EI-MS $m / z(\%): 236\left(\mathrm{M}^{+}, 55\right), 194(50), 163$ (100), 138 (37), 91 (13). HR-MS $m / z$ : 236.1408 (Calcd for $\mathrm{C}_{14} \mathrm{H}_{20} \mathrm{O}_{3}: 236.1412$ ).

$\mathrm{N}$-(2,6-Dimethylphenyl)-2-oxocyclohexanecarbamide (18): White needles. mp $135.8-136.6^{\circ} \mathrm{C}$ (benzene). IR (KBr) cm ${ }^{-1}$ : 3416, 3233, 3040, $2945,2869,1708,1647,1542,1478,1376,1129,769,690 .{ }^{1} \mathrm{H}-\mathrm{NMR}$ $\left(\mathrm{CDCl}_{3}\right) \delta: 1.71-1.93(2 \mathrm{H}, \mathrm{m}), 1.94-2.20(3 \mathrm{H}, \mathrm{m}), 2.23(6 \mathrm{H}, \mathrm{s}), 2.42-$ $2.65(3 \mathrm{H}, \mathrm{m}), 3.41(1 \mathrm{H}, \mathrm{dd}, J=6.0,11.5 \mathrm{~Hz}), 7.04-7.13(3 \mathrm{H}, \mathrm{m}), 8.64(1 \mathrm{H}$, br s). EI-MS $m / z$ (\%): $245\left(\mathrm{M}^{+}, 38\right), 147$ (37), 121 (100), 98 (23), 55 (12). HR-MS $m / z$ : 245.1412 (Calcd for $\mathrm{C}_{15} \mathrm{H}_{19} \mathrm{NO}_{2}: 245.1416$ ).

$N$-(2,6-Dimethylphenyl)-7-oxo-1,3,4,5,6,7-hexahydro- $2 H$-naphthalene4a-carbamide (19): White needles. mp 213.3-214.5 ${ }^{\circ} \mathrm{C}$ (benzene). $\mathrm{IR}(\mathrm{KBr})$ $\mathrm{cm}^{-1}: 3311,2941,2859,1664,1540,1264,1220,782 .{ }^{1} \mathrm{H}-\mathrm{NMR}\left(\mathrm{CDCl}_{3}\right) \delta$ : $1.30-2.28(6 \mathrm{H}, \mathrm{m}), 2.22(6 \mathrm{H}, \mathrm{s}), 2.29-2.88(6 \mathrm{H}, \mathrm{m}), 6.13(1 \mathrm{H}, \mathrm{s}), 7.02-$ $7.15(3 \mathrm{H}, \mathrm{m}), 7.92(1 \mathrm{H}, \mathrm{s})$. EI-MS $m / z(\%): 297\left(\mathrm{M}^{+}, 27\right), 151(11), 150$ (100), 149 (12), 148 (14), 147 (53), 132 (18), 122 (15), 121 (18), 119 (24), 118 (17), 108 (36), 107 (11), 105 (12), 93 (25), 91 (20), 79 (19), 77 (14). HR-MS $m / z$ : 297.1728 (Calcd for $\mathrm{C}_{19} \mathrm{H}_{23} \mathrm{NO}_{2}:$ 197.1729). Anal. Calcd for $\mathrm{C}_{19} \mathrm{H}_{23} \mathrm{NO}_{2}: \mathrm{C}, 76.73 ; \mathrm{H}, 7.80 ; 4.71$. Found: C, 76.71; H, 7.87; N, 4.51.

Acknowledgments This work was supported by a Grant-in-Aid for Encouragement of Young Scientists No. 12771368 from the Ministry of Education, Culture, Sports, Science and Technology, Japan. 


\section{References and Notes}

1) Caddlick S., Tetrahedron, 51, 10403-10432 (1995).

2) Loupy A., Petit A., Hamelin J., T.-Boullet F., Jacquault P., Mathé D., Synthesis, 1998, 1213-1234 (1998).

3) Takatori K., Hasegawa K., Narai S., Kajiwara M., Heterocycles, 42, 525-528 (1996).

4) Comprehensive Organic Synthesis: Selectivity, Strategy, and Efficiency in Modern Organic Chemistry, Vol. 2, 4, eds. by Trost B. M., Fleming I., Pergamon Press, New York, 1991.

5) Rapson W. S., Robinson R., J. Chem. Soc., 1935, 1285-1288 (1935).

6) Ramachandran S., Newman M. S., "Organic Syntheses," Coll. Vol. V, ed. by Baumgarten H. E., John Wiley and Sons, Inc., New York, 1973, pp. $486-488$.

7) For solvent-free Robinson annulation with sodium methoxide, see: Miyamoto H., Kanetaka S., Tanaka K., Yoshizawa K., Toyota S., Toda F., Chem. Lett., 2000, 888-889 (2000).
8) Ho T.-L., "Carbocycle Construction in Terpene Synthesis," VCH Publishers Inc., New York, 1988.

9) Another Robinson annulation under microwave irradiation, see: Rissafi B., Louzi A. E., Loupy A., Petit A., Soufiaoui M., Tétouani S. F., Eur. J. Org. Chem., 2002, 2518-2523 (2002).

10) Ranu B. C., Bhar S., Sarkar D. C., Tetrahedron Lett., 32, 2811-2812 (1991).

11) Ranu B. C., Bhar S., Tetrahedron, 48, 1327-1332 (1992).

12) For organic reaction on alumina, see: Posner G. H., Angew. Chem. Int. Ed. Engl., 17, 487-496 (1978).

13) For organic reaction on alumina, see: Kabalka G. W., Pagni R. M., Tetrahedron, 53, 7999-8065 (1997).

14) Amide 18 was prepared from the ester $\mathbf{1 1}$ and 2,6-xylidine under microwave irradiation, see: Suri O. P., Satti N. K., Suri K. A., Syn. Commun., 30, 3709-3718 (2000).

15) Ranu B. C., Saha M., Bhar S., Syn. Commun., 27, 621—626 (1997). 